20

\title{
Фотоиндуцированное усиление флуоресценции красителя эванса синего в водном растворе альбумина*
}

\author{
(C) А.А. Намыкин ${ }^{1}$, А.П. Хороводов ${ }^{1}$, О.В. Семячкина-Глушковская ${ }^{1}$, В.В. Тучин ${ }^{1,2,3}$, И.В. Федосов ${ }^{1}$ \\ ${ }^{1}$ Саратовский национальный исследовательский государственный университет имени Н.Г. Чернышевского, \\ 410012 Саратов, Россия \\ ${ }^{2}$ Национальный исследовательский Томский государственный университет, \\ 634050 Томск, Россия \\ ${ }^{3}$ Институт проблем точной механики и управления РАН, \\ 410028 Саратов, Россия \\ e-mail: anton-namikin@bk.ru
}

Поступила в редакцию 23.11.2018 г.

В окончательной редакции 26.01.19 г.

Принята к публикации 31.01.2019 г.

\begin{abstract}
Рассмотрен эффект фотоиндуцированного усиления флуоресценции красителя эванс синий (ЕВ) в плазме крови и растворе альбумина. Сравнены проявления эффекта усиления флуоресценции красителя в растворе альбумина и в плазме крови крысы. Впервые обнаружено насыщение фотоиндуцированной флуоресценции, эффект запаздывания усиленной флуоресценции и расхождения в спектрах флуоресценции растворов. На основе полученных результатов предложена гипотеза о присутствии не флуоресцирующих комплексов с участием ЕВ в плазме крови.
\end{abstract}

DOI: $10.21883 /$ OS.2019.05.47664.13-19

\section{Введение}

Эванс синий (Evans Blue dye, EB) является тетранатрий диазо-органической солью с молекулярной массой 960.8 a.u. [1]. Не флуоресцирует в водных растворах, слабая флуоресценция наблюдается в спиртовых растворах. Имеет сродство к белкам и образует в плазме крови флуоресцентные комплексы с альбумином и глобулином [2]. Флуоресценция комплексов эванса синего и белков наблюдается на длине волны $680 \mathrm{~nm}$ для длины волны возбуждения $620 \mathrm{~nm}$. При попадании в организм EB не нарушает циркуляционные процессы, не проникает в мембраны живых клеток [3]. Имеет долгое время выведения, фотообесцвечивание экспериментально не наблюдается [4]. Эванс синий используется для изучения целостности мембран [5] и исследования проницаемости гематоэнцефалического барьера (ГЭБ) при различных патологиях [6-11].

Азокрасители являются классом цветных органических соединений, которые используются как красители и пигменты. Особенностью данного класса соединений является наличие одной или нескольких азогрупп $-\mathrm{N}=$ $=\mathrm{N}-$, связывающих ароматические или гетероароматические остатки, соединяющиеся друг с другом или с остатками соединений, имеющих активные $\mathrm{CH}_{2}$-группы. За счет вращения молекулярных групп вокруг центральной связи происходит цис-транс-изомеризация молекул.

\footnotetext{
* The 22nd Annual Conference Saratov Fall Meeting 2018 (SFM'18): VI International Symposium, „Optics and Biophotonics“ and XXII International School for Junior Scientists and Students on Optics, Laser Physics \& Biophotonics, September 24-29, 2018, Saratov, Russia. https://www.sgu.ru/structure/fiz/saratov-fall-meeting/previousconferences/sara
}

Впервые эффект иис-транс-изомеризации был обнаружен у молекул азобензола и его производных [12]. Обычно молекулы азобензола находятся в транс-форме, а при воздействии света могут быть преобразованы в цисформу. Реакция фотохимического цис-транс-преобразования является обратимой, скорость восстановления изомеризации напрямую зависит от агрегатного состояния вещества, твердое вещество сохраняет изомеризацию длительное время даже при фотовоздействии. Позже были синтезированы флуоресцентные красители на основе азокрасителей, а также обнаружено, что флуоресценция в цис-состоянии более эффективна, чем в транссостоянии. Как следствие изомеризации, наблюдалась усиленная люминесценция, объясненная непланарной геометрией цис-изомера молекулы. На данный момент сообщалось о наблюдении данного эффекта в тонких пленках [13], растворах и полимерных матрицах [14].

В работе [15] нами был обнаружен эффект фотоиндуцированного усиления флуоресценции ЕВ в растворе плазмы крови при предварительном воздействии интенсивным лазерным излучением $\left(2 \cdot 10^{5} \mathrm{~W} / \mathrm{cm}^{2}\right)$ с длиной волны $635 \mathrm{~nm}$ или $405 \mathrm{~nm}$, интенсивность флуоресценции увеличивается на $50 \%$ [15]. При этом воздействие фиолетового лазера приводило к более слабому проявлению эффекта. Было установлено, что время жизни фотоиндуцированного усиления флуоресценции составляет около $1 \mathrm{~s}$. В работе [15] нами использовались два одинаковых полупроводниковых лазера с длиной волны $635 \mathrm{~nm}$, излучение одного из которых, „пишущего“ лазеpa, было сфокусировано в тонкую линию поперек кровеносного сосуда и использовалось для локального усиления флуоресценции путем предварительного облучения 
плазмы крови с введенным в нее красителем. Излучение второго лазера, так называемого „считывающего“, было расфокусировано так, чтобы обеспечить равномерное освещение поля зрения микроскопа. „Считывающий“ лазер был синхронизирован с камерой микроскопа и использовался для возбуждения флуоресценции красителя.

Исследование эффекта усиления интенсивности флуоресценции при различной мощности „пишущего“ и „считывающего“ лазеров выявило слабую зависимость интенсивности от мощности „считывающего“ лазера.

Мы продемонстрировали применение эффекта для прижизненного измерения методом флуоресцентной молекулярной метки скорости кровотока в капиллярах и сосудах различного диаметра. Данные, полученные в ходе работы, позволили сделать вывод, что эффект фотоиндуцированной флуоресценции связан с циис-трансизомеризацией молекул ЕВ в связанном состоянии с белками альбумина. Мы впервые наблюдали возможность фотоиндуцированного усиления флуоресценции в растворах плазмы крови, а также в составе цельной крови прижизненно.

Исследования сродства ЕВ в плазме крови проводились с различными фракциями белков, выделенных из плазмы крови человека, после осаждения несвязанного красителя; считалось количество связанного с белком красителя при помощи фотоэлектрического колориметра. Было выявлено, что в плазме крови ЕВ образует комплексы с белками альбумина и глобулина [2]. В настоящей работе мы исследовали и сопоставили проявление эффекта в водном растворе альбумина и в плазме крови при одинаковых условиях. Наше исследование позволило провести качественную оценку проявления эффекта в условиях отсутствия прочих белков плазмы крови и непосредственно в плазме крови in vitro. Проведено спектральное исследование флуоресценции растворов ЕВ плазмы крови и альбумина, и установлено расхождение спектров флуоресценции в длинноволновой области. Обнаружен эффект насыщения и запаздывания усиленной флуоресценции.

\section{1. Материалы и методы}

\section{1. Экспериментальная установка}

Для наблюдения флуоресценции комплексов $\mathrm{EB}+$ альбумин и изучения эффекта увеличения интенсивности флуоресцентного сигнала был разработан флуоресцентный микроскоп (рис. 1). Оптическая система микроскопа состоит из объектива с числовой апертурой 0.30 (тубус „бесконечность“, фокусное расстояние $13.89 \mathrm{~mm}$ ) и тубусной линзы с фокусным расстоянием $150 \mathrm{~mm}$ (LA1433, Thorlabs Inc, США). Регистрация сигнала производилась с помощью CMOS-камеры (acA1920-40uc, Basler AG, Германия). Разрешение камеры составляет $1920 \times 1200$ пикселей и максимальная частота кадров $41 \mathrm{fps}$ в режиме полнокадровой съемки. Масштаб изображения составлял

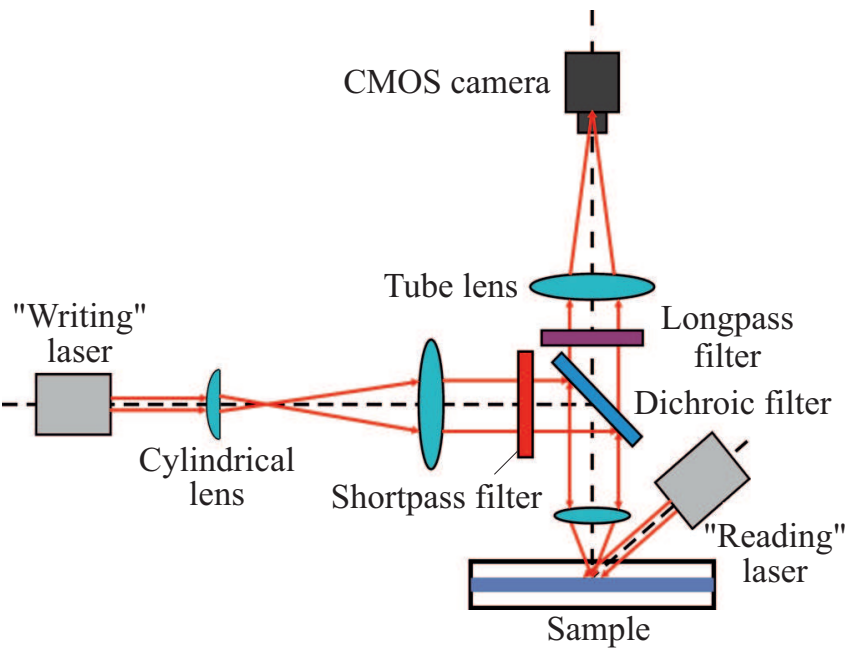

Рис. 1. Экспериментальная установка.

$0.5 \mu \mathrm{m}$ в плоскости предмета на один пиксель. Раствор красителя вводился в цилиндрическую стеклянную капиллярную трубочку с наружным диаметром $700 \mu \mathrm{m}$ и внутренним диаметром $100 \mu \mathrm{m}$. Лазерный диодный модуль (50000463, Laserlands.net, Китай), с выходной мощностью $160 \mathrm{~mW}$ и длиной волны $635 \mathrm{~nm}$ использовался для возбуждения флуоресценции красителя, т.е. в качестве „считывающего“ источника света. Коллимированный пучок лазерного модуля направлялся в предметную плоскость микроскопа под углом $45^{\circ}$ относительно оптической оси микроскопа. Диаметр пучка $3 \mathrm{~mm}$ обеспечивал квазиравномерное освещение в пределах поля зрения микроскопа размером $0.8 \times 0.6 \mathrm{~mm}$. Чтобы уменьшить облучение образца, лазер был синхронизирован с триггером камеры и включался только в период регистрации изображения. Плотность мощности „считывающего“ лазера в предметной плоскости микроскопа составляла $0.8 \mathrm{~W} / \mathrm{cm}^{2}$. Для наблюдения флуоресценции использовался набор флуоресцентных фильтров (49019-ET-Cy5 Longpass, Chroma Technology Corp., США). Второй лазерный диодный модуль, идентичный „считывающему“ (50000463, Laserlands.net, Китай), с выходной мощностью $160 \mathrm{~mW}$ и длиной волны $638 \mathrm{~nm}$ использовался в качестве „Пишущего“ источника света для фотоиндуцированного усиления флуоресценции молекул $\mathrm{EB}$. „Пишущий“ лазер с его оптической системой был установлен в порт осветителя микроскопа. Его излучение фокусировалось цилиндрической линзой $\left(f^{\prime}=70 \mathrm{~mm}\right)$ и сферической линзой $f^{\prime}=75 \mathrm{~mm}$ (Thorlabs, LA1608-A) в линию, оптически сопряженную с предметной плоскостью микроскопа. Затем излучение лазера проходило через фильтр возбуждения и направлялось в зрачок объектива микроскопа при помощи дихроичного зеркала. Линия, проецируемая „пишущим лазером“ в предметную плоскость микроскопа, имела размер $200 \times 3 \mu \mathrm{m}$ по уровню падения интенсивности в $e$ раз. Капиллярная 
трубочка располагалась на предметном столе микроскопа таким образом, чтобы ее ось пересекала спроецированную линию приблизительно посередине и под прямым углом. Средняя плотность мощности излучения „пишущего“ лазера в предметной плоскости микроскопа составляла $2.05 \cdot 10^{5} \mathrm{~W} / \mathrm{cm}^{2}$. Измерение производилось с помощью измерителя мощности (Optical power meter Model 1815-C, Newport Corp. USA).

\section{2. Модель наблюдаемых процессов}

Модель наблюдаемых процессов можно представить в виде последовательности четырех трансформаций:

$$
X \stackrel{\hbar \omega}{\longrightarrow} X \stackrel{T_{\mathrm{pc}}}{\longrightarrow} Z \stackrel{T_{\mathrm{rec}}}{\longrightarrow} X,
$$

где $X$ - молекула ЕВ, находящаяся в транс-изомерном состоянии, при поглощении фотона с некоторой вероятностью $P(\hbar \omega)$ переходит в состояние $Y$, при котором молекула красителя находится в цис-изомерном состоянии. После этого происходит переход в состояние $Z$ и нарастание флуоресценции (эффект запаздывания усиленной флуоресценции) со временем $T_{\mathrm{pc}}$ (рис. 3). Далее следует спонтанная реконверсия в изначальное состояние $X$

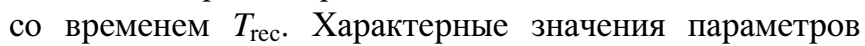
модели приведены в таблице.

\section{3. Подготовка растворов красителя Evans Blue}

Выделение плазмы осуществлялось из крови самца крысы линии Wistar возрастом 4 месяца. Перед забором крови в кровоток через полиэтиленовый катетер диаметром $0.58 \mathrm{~mm}$ (Smiths Medical International, США) в сонную артерию вводили $0.5 \mathrm{ml} 0.1 \%$ раствора ЕВ. Раствор циркулировал в кровотоке $1 \mathrm{~h}$ с момента введения. Далее собирали кровь путем пункции сердца. Собранную в пробирку с антикоагулянтом кровь центрифугировали в течение $30 \mathrm{~min}$ при частоте вращения $2000 \mathrm{rpm}$. Отделяли плазму от форменных элементов микропипеткой в стерильную пробирку эппендорфа, таким образом, концентрация ЕВ в случае полной связи с белками плазмы и полном объеме циркулирующей крови $5.5 \mathrm{ml}$ предположительно составила $0.09 \%$. Фактическая концентрация ЕВ отличается от этого значения в меньшую сторону по причине связывания части красителя в организме. Для приготовления раствора ЕВ и альбумин смешали $1 \mathrm{ml}$ 10\%-раствора альбумина (Sigma Сент-Луис, Миссури, США) в физиологическом растворе с $1 \mathrm{ml} 0.1 \%$ раствора Evans Blue (Sigma Сент-Луис, Миссури, США) в физиологическом растворе. Концентрация ЕВ в готовом растворе составляла $0.05 \%$.

\section{2. Результаты и обсуждение}

Измерение интенсивности флуоресценции исследуемого раствора, помещенного в капиллярную трубочку,
Характерные времена нарастания флуоресценции и реконверсии

\begin{tabular}{c|c|c}
\hline \multirow{2}{*}{ Параметр, s } & \multicolumn{2}{|c}{ Система с ЕВ } \\
\cline { 2 - 3 } & Альбумин+ЕВ & Плазма+ЕВ \\
\hline$T_{\mathrm{pc}}$ & 0.045 & 0.3 \\
$T_{\mathrm{rec}}$ & 1.32 & 2
\end{tabular}
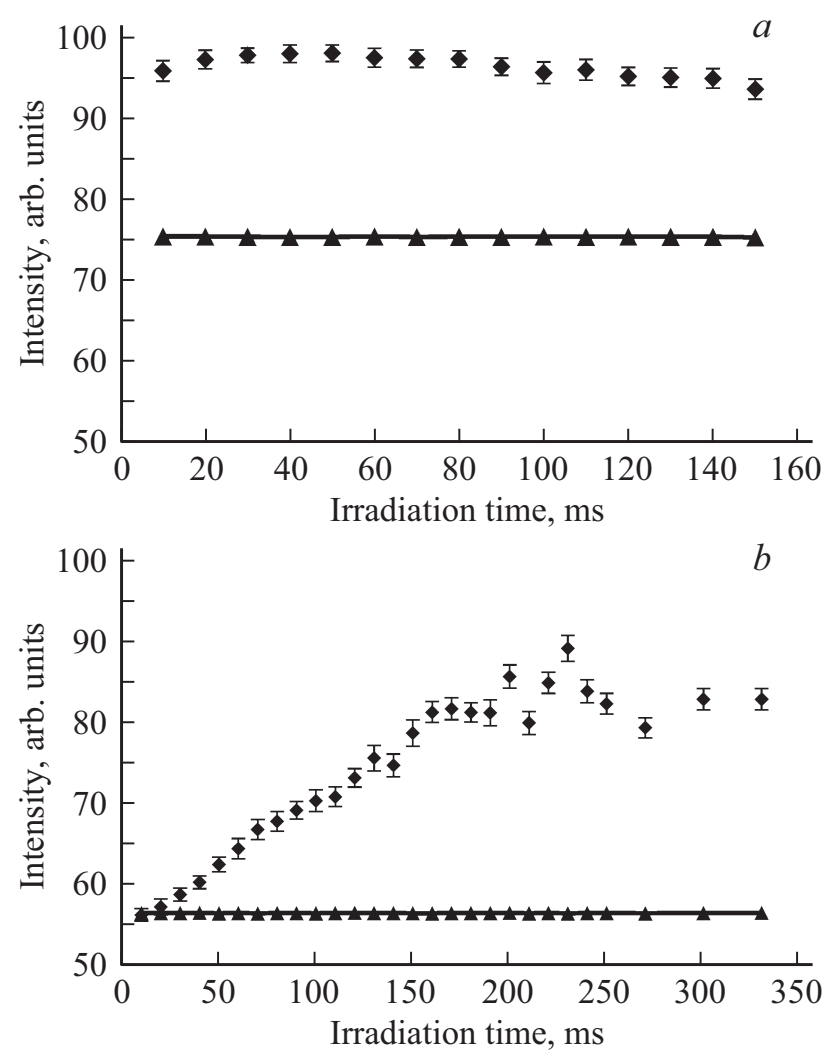

Рис. 2. Максимальные значения интенсивности флуоресценции $(\checkmark)$ в зависимости от продолжительности воздействия „Пишущего“ лазера; $(a)$ для раствора ЕВ и альбумина, $(b)$ раствор EВ и плазма. Треугольником (ム) обозначена интенсивность флуоресценции области без воздействия „пишущего“ лазера.

осуществлялось при помощи камеры микроскопа. Зависимость фотоиндуцированного усиления флуоресценции от продолжительности воздействия „пишущего“ лазера исследовалась при постоянной длительности экспозиции $5 \mathrm{~ms}$. Поскольку „считывающий“ лазер был синхронизирован с камерой микроскопа, длительность импульсов его излучения также составляла $5 \mathrm{~ms}$.

Для измерения интенсивности флуоресценции регистрировались две серии по 100 кадров, с частотой кадров $100 \mathrm{fps}$. Первая серия регистрировалась до, а вторая после облучения раствора красителя ,пишущим“ лазером. Интенсивность флуоресценции раствора, измеренная по кадрам первой серии, использовалась в качестве базового уровня флуоресценции. Максимальное значение интенсивности флуоресценции в области, 


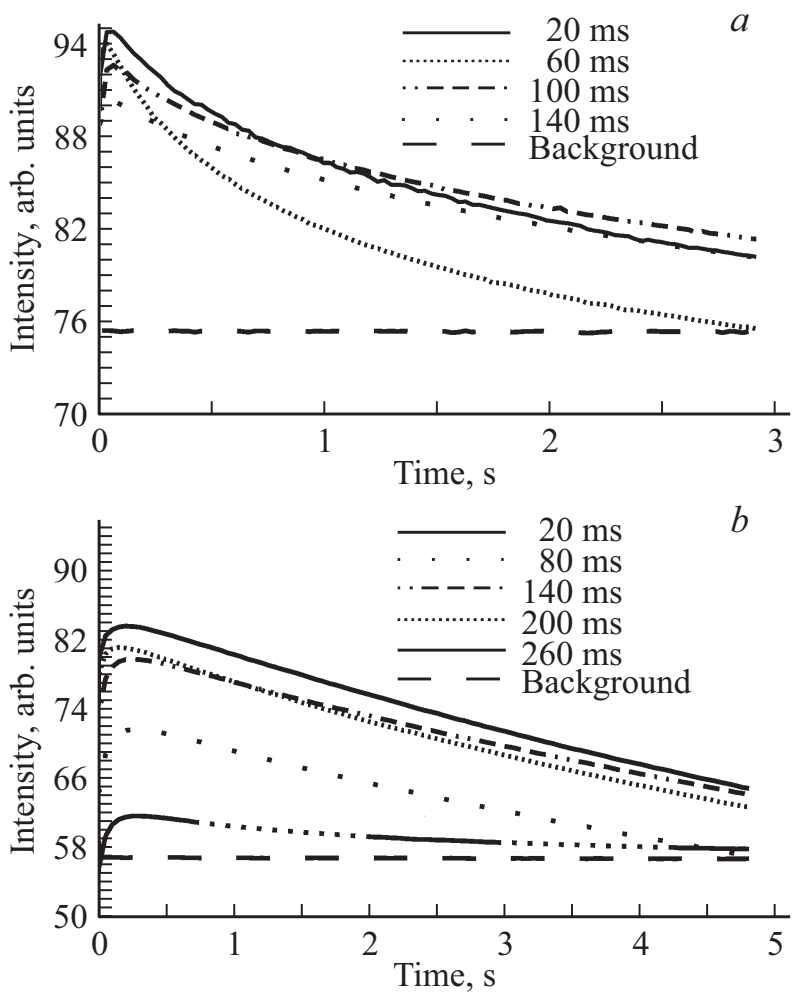

Рис. 3. Зависимость интенсивности флуоресценции от времени после воздействия „пишущего“ лазера; (a) раствор альбумин и ЕВ; $(b)$ раствор плазма и $\mathrm{EB}$.

облученной „пишущим“ лазером, вычислялось по кадрам второй серии. На рис. 2 представлена зависимость максимального значения флуоресценции раствора в области воздействия „пишущего“ лазера в зависимости от продолжительности воздействия (ромбы), для раствора EB и альбумина $(a)$ и для раствора ЕВ и плазмы крови $(b)$. Базовая интенсивность флуоресценции на рис. 2 обозначена треугольниками.

В связи с конструктивными особенностями системы управления „пишущим“ лазером минимально возможная продолжительность облучения образца не могла быть менее $10 \mathrm{~ms}$. Для каждой точки на рис. 2 производилась прокачка раствора на объем, соответствующий полной смене раствора в поле зрения микроскопа, чтобы исключить возможность переоблучения раствора.

Из рис. 2, $a$ видно, что эффект не зависит от продолжительности воздействия. Это может быть объяснено насыщением фотоиндуцированного усиления флуоресценции даже при минимальной продолжительности воздействия $10 \mathrm{~ms}$. Фотоиндуцированное усиление флуоресценции составляет 28\% от интенсивности флуоресценции раствора до облучения его „пишущим“ лазером. Для раствора плазмы крови (рис. 2, $b$ ) наблюдается устойчивое увеличение интенсивности фотоиндуцированной флуоресценции при увеличении продолжительности воздействия в пределах от $10 \mathrm{~ms}$ до $150 \mathrm{~ms}$. При дальнейшем увеличении продолжительности воздействия из- лучения „Пишущего“ лазера на раствор плазмы крови в пределах от 160 до $330 \mathrm{~ms}$ максимальный прирост интенсивности остается неизменным и составляет приблизительно $36 \%$.

Эффект насыщения фотоиндуцированной флуоресценции раствора ЭС с плазмой крови сохраняется в пределах длительностей включения пишущего лазер до $350 \mathrm{~ms}$. В случае раствора альбумина наблюдается небольшой спад интенсивности при увеличении длительности воздействия „пишущего“ лазера более $50 \mathrm{~ms}$. В случае наблюдения водного раствора ЭС, свободного от белков, флуоресценция не наблюдалась, и был виден лишь шумовой сигнал от матрицы камеры порядка 2 относительных единиц.

Из рис. 3 видно, что время затухания эффекта фотоиндуцированного увеличения флуоресценции для раствора плазмы (рис. $3, b)$ в 1.5 раза больше, чем для раствора альбумина (рис. $3, a$ ). Время затухания фотоиндуцированной флуоресценции до половины интенсивности от максимальной для раствора плазмы крови составило $2 \mathrm{~s}$, а для раствора альбумина $1.32 \mathrm{~s}$. Также из графика видно, что эффект проявляется не сразу, а лишь спустя некоторое время. Данное время запаздывания не зависит от длительности облучения „пишущего“ лазера и соответствует для плазмы крови $300 \pm 10 \mathrm{~ms}$, а для раствора альбумина $45 \pm 15 \mathrm{~ms}$.

Спектр флуоресценции раствора плазмы крови и ЕВ (рис. 4) смещен относительно спектра флуоресценции альбумина и $\mathrm{EB}$ (рис. 4) на $17 \mathrm{~nm}$ в длинноволновую область. Данное изменение спектра флуоресценции можно объяснить присутствием других флуоресцирующих комплексов, таких как комплексы глобулина и ЕВ. Эффект фотоиндуцированного усиления флуоресценции ЕВ проявляется в растворах плазмы крови и альбумина. Эффект обладает свойством насыщения. В случае с использованием раствора альбумина насыщение имеет место даже при минимальных дозах воздействия, осуществимых в нашей экспериментальной установке. Для раствора ЕВ в плазме крови минимальная продолжительность облучения для проявления эффекта насыщения

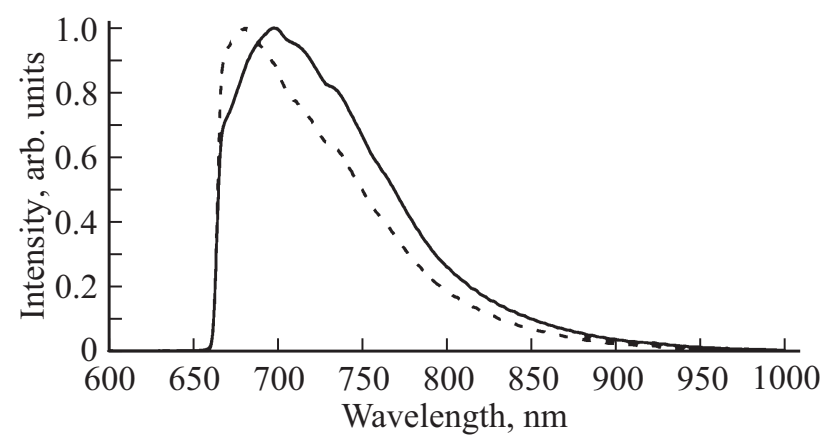

Рис. 4. Спектры флуоресценции раствора альбумина и ЕВ (штриховая линия), раствора плазма крови и ЕВ (сплошная линия). Резкая граница спектра около $660 \mathrm{~nm}$ обусловлена присутствием барьерного светофильтра в системе. Длина волны возбуждения $635 \mathrm{~nm}$. 
составила $160 \mathrm{~ms}$. Данное различие можно объяснить различной концентрацией красителя ЕВ в растворах, поскольку максимальный прирост интенсивности при достижении порога насыщения в обоих случаях остается практически одинаковым относительно базового уровня флуоресценции 28\% у раствора альбумина и $36 \%$ у раствора плазмы крови. Но базовый уровень интенсивности для раствора альбумина на $36 \%$ больше, чем для плазмы крови.

В ходе работы были установлены следующие экспериментальные факты:

1) Интенсивность флуоресценции возрастает по мере увеличения дозы и достигает некоторого значения насыщения, которое остается практически неизменным при дальнейшем увеличении дозы.

2) Значения этого насыщения практически совпадают и для плазмы, и для альбумина.

3) Насыщение в плазме достигается при дозе 10 раз больше, чем в альбумине.

Из первого и второго можно предположить, что концентрация светящихся комплексов примерно одинакова и в плазме, и в альбумине. Из третьего следует, что доза для комплексов в плазме в 10 раз ниже, чем в альбумине. Из этого следует, что в плазме присутствуют какие-то соединения, которые поглощают излучение лазера, и эффективная доза из-за этого оказывается в плазме в 10 раз меньше. Например, не флуоресцирующие комплексы ЕВ или свободный ЕВ. Впрочем, последнее маловероятно с учетом высокой аффинности ЕВ к белкам плазмы. Данная гипотеза требует дальнейшей экспериментальной проверки.

Время релаксации до половины от максимума интенсивности раствора альбумина составило $1.32 \mathrm{~s}$ и в растворе плазмы крови $2 \mathrm{~s}$ при одинаковых значениях времени облучения. Был обнаружен эффект запаздывания фотоиндуцированного усиления флуоресценции, ранее не описанный для данного красителя. При этом в растворе альбумина процесс занимал в восемь раз меньше времени, чем в плазме крови. Спектр флуоресценции водного раствора альбумина и $\mathrm{EB}$ полностью соответствует ранее опубликованному в литературе спектру с максимумом на $680 \mathrm{~nm}$. В данной работе нами обнаружено, что максимум спектра флуоресценции ЕВ в растворе плазмы крови наблюдается на длине волны $697 \mathrm{~nm}$, то есть сдвинут на $17 \mathrm{~nm}$ в длинноволновую область.

Эффект фотоиндуцированного усиления флуоресценции ЕВ по своим свойствам схож с эффектом фотообесцвечивания для классических флуоресцентных красителей, который применяется для измерений скорости жидкостей и газов методом молекулярной метки (MTV). Однако ЕВ имеет ряд характерных отличий. После воздействия „пишущего“ лазера комплексы не разрушаются и поэтому могут быть повторно использованы в дальнейшем исследовании. Большая часть классических флуоресцентных красителей, таких как флуоресцеин, родамин и их производные требуют коротковолнового возбуждения, что в случае прижизненных исследований оказывает фотоинтоксикацию на окружающие ткани. Спектр возбуждения ЕВ находится в длинноволновой области 630-640 nm, в этой части поглощения биологических тканей минимально, что позволяет увеличивать дозы и продолжительность воздействия без вреда для организма.

\section{Заключение}

В настоящей работе нами экспериментально исследовано проявление эффекта фотоиндуцированного усиления флуоресценции для растворов ЕВ с плазмой крови и альбумина. В результате нами впервые установлены эффект насыщения фотоиндуцированной флуоресценции, эффект запаздывания усиленной флуоресценции и расхождения в спектрах флуоресценции растворов. На основе полученных результатов нами предложена гипотеза о присутствии не флуоресцирующих комплексов с участием ЕВ в плазме крови.

Дальнейшее исследование эффекта фотоиндуцированного усиления флуоресценции является значимым для прикладных и фундаментальных направлений в микроскопии, цитометрии и флоуметрии. Одно из возможных направлений для развития данного эффекта является использование в качестве красителя тканей для конфокальной микроскопии, так как ЕВ не обесцвечивается, обладает высоким сродством к различным белкам, что открывает перспективу для разработки метода многоточечного контроля движения молекул красителя как в кровеносном сосуде, так и в межклеточном пространстве вокруг него. Детальное изучение эффекта фотоиндуцированного усиления флуоресценции и структуры красителя, обусловливающей его проявление, может послужить ключом к разработке принципиально новых флуоресцентных маркеров, в том числе и на основе флуоресцентных белков, обладающих уникальными свойствами и устойчивых к обесцвечиванию.

\section{Финансирование работы}

Исследования поддержаны грантом РНФ № 17-7520069, И.В. Федосов благодарит Минобрнауки РФ за поддержку в рамках проекта № 3.550.2017/6.7.

\section{Соблюдение этических стандартов}

Все применимые международные, национальные и/или институциональные принципы ухода и использования животных были соблюдены.

\section{Список литературы}

[1] Freedman F.B., Johnson J.A. // Am. J. Physiol. Content. American Physiological Society. 1969. V. 216. N 3. P. 675.681. 
[2] LeVeen H.H., Fishman W.H. // Am. J. Physiol. Content. American Physiological Society. 1947. V. 151. N 1. P. 26-33.

[3] Gaff D.F., Okong.o-ogola O.T. // J. Exp. Bot. 1971. V. 22. N 3. P. 756-758.

[4] Gibson J.G., Evans W.A. // J. Clin. Invest. 1937. V. 16. N 3. P. 301-316.

[5] Hamer P.W. et al. // J. Anat. 2002. V. 200. N 1. P. 69-79.

[6] Jacyn Baker C., Mock N.M. // Plant Cell. Tissue Organ Cult. 1994. V. 39. N 1. P. 7-12.

[7] Rogers D.F., Boschetto P., Barnes P.J. // J. Pharmacol. Methods. 1989. V. 21. N 4. P. 309-315.

[8] McDonald D.M., Blewett R.W. // J. Neurocytol. 1981. V. 10. N 4. P. 607-643.

[9] Patterson C.E., Rhoades R.A., Garcia J.G. // J. Appl. Physiol. 1992. V. 72. N 3. P. $865-873$.

[10] El'Sayed H., Goodall S.R., Hainsworth R. // Clin. Lab. Haematol. 1995. V. 17. N 2. P. 189-194.

[11] Michalicova A. et al. // J. Liq. Chromatogr. Relat. Technol. 2017. V. 40. N 9. P. $442=448$.

[12] Hartley G. // Nature. 1937. V. 140. N 3537. P. 281.

[13] Haruta O., Matsuo Y., Ijiro K. // Colloids Surfaces A Physicochem. Eng. Asp. Elsevier, 2008. V. 313. P. 595-599.

[14] Smitha P., Asha S.K. // J. Phys. Chem. B. 2007. Vol. 111. N 23. P. 6364-6373.

[15] Namykin A.A. et al. // J. Biophotonics. 2018. P. e201700343. 